\title{
Factors associated with late presentation of cervical cancer cases at a district hospital: a retrospective study
}

\author{
Priscilla Dunyo ${ }^{1}$, Kofi Effah ${ }^{2}$ and Emilia Asuquo Udofia ${ }^{3^{*}}$ (D)
}

\begin{abstract}
Background: Cervical cancer is the leading and most common female cancer among women in Ghana. Although there are screening methods to detect premalignant lesions for treatment, screening coverage in Ghana is $2.8 \%$ and late presentation of cases complicates treatment efforts.

This study examined the sociodemographic, clinical and histological characteristics associated with late presentation of cervical cancer cases attending Gynecological Oncology care at Catholic Hospital, Battor.

Methods: One hundred and fifty-seven medical records of confirmed cases of cervical cancer reporting to the Outpatient Obstetrics and Gynecology Department between 2012 and 2016 were reviewed. Relevant data were retrieved using abstraction forms. Socio demographic variables investigated were level of education attained, marital status, National Health Insurance Scheme membership, employment status, place of residence and distance from hospital. Clinical variables included intermenstrual/postmenopausal bleeding, previous screening history, previous smoking history, age at menarche and number of children. Histological variables included subtypes of tumour and characteristics of tumour. Pearson's chi-square test and logistic regression analysis were used to determine correlates of late stage at presentation with cervical cancer. Sensitivity analysis was performed to assess the effect of missing data.
\end{abstract}

Results: Approximately two-thirds (65.97\%) of the cases presented in advanced stages of cervical cancer. Level of education, age at menarche and previous screening history were included in a regression model and adjusted for age. Age at menarche $(n=66)$ was eliminated from the model after sensitivity analysis. Among the remaining variables, only previous screening history was predictive of late stage at presentation of cervical cancer cases. Previously unscreened cases of cervical cancer were nearly four times more likely to present late, compared to those who had been screened previously (OR 3.91; 95\% Cl 1.43-10.69). No association was observed with sociodemographic and histological characteristics.

Conclusion: Lack of previous screening was associated with late presentation of cervical cancer at Catholic Hospital, Battor. Efforts to promote early cervical cancer screening should be intensified and future studies may explore an association with age at menarche.

Keywords: Cervical cancer, Ghana, Oncology, Screening, Prevention

\footnotetext{
* Correspondence: emiliaudf@yahoo.com

${ }^{3}$ Department of Community Health, School of Public Health, University of

Ghana, Legon, Accra, Ghana

Full list of author information is available at the end of the article
}

(c) The Author(s). 2018 Open Access This article is distributed under the terms of the Creative Commons Attribution 4.0 International License (http://creativecommons.org/licenses/by/4.0/), which permits unrestricted use, distribution, and reproduction in any medium, provided you give appropriate credit to the original author(s) and the source, provide a link to the Creative Commons license, and indicate if changes were made. The Creative Commons Public Domain Dedication waiver (http://creativecommons.org/publicdomain/zero/1.0/) applies to the data made available in this article, unless otherwise stated. 


\section{Background}

Cervical cancer has been reported to account for a third of all female cancers in Ghana and the World Health Organization (WHO) has predicted that it will account for 5000 new cases by the year 2025 [1]. It further predicts 3361 deaths will occur annually. In spite of the grim picture painted, there is no organized national screening programme in Ghana [2]. As a first step, a national policy was developed in 2011 as part of the National Cancer Control Plan. The policy recommends Visual Inspection with Acetic Acid (VIA) as a screening method, with cryotherapy as treatment, for women aged 25-45 years found to have a pre-malignant lesion. Cytology has been recommended for women aged 45 years and older [3].

Screening coverage for cervical cancer in Ghana is reportedly low at $2.8 \%$, with the majority of women diagnosed when the disease is advanced [1]. This is not different from what occurs in other developing countries. For instance, in a hospital based, cross sectional study in Uganda, $66 \%$ of the study participants reported in advanced stages of cervical cancer [4]. Another study conducted in Tanzania reported that $63.9 \%$ of its study participants presented late to the healthcare facility [5]. An ecological study investigated population-level exposure to risk factors in relation to late stage cervical cancer and found that gross domestic product, HIV infection, non-use of condoms, high parity and lack of formal education were significant predictors [6]. A recent study conducted in two regions in Ghana, also reported that late stage presentation was common [7].

Previous studies have shown that low socioeconomic status is associated with late presentation of cervical cancer $[8,9]$. In addition, other factors such as race, age at diagnosis $[8,10]$, insurance status $[11,12]$, marital status $[4,13]$, educational status [14], place of residence $[15,16]$, number of children [4] and screening practices [17] have been associated with the stage at presentation, which in turn affect survival rates. The ability to identify abnormal genital tract bleeding symptoms (post-menopausal bleeding or intermenstrual bleeding) can affect health seeking behaviour, while indicative results from previous screening, family history of cervical cancer, personal history of sexually transmitted infections and smoking contribute to the development of cervical cancer [13, 14]. There is also evidence that biological behaviour of the tumour predicts the stage at diagnosis $[5,18,19]$.

Human papilloma virus DNA testing is the recommended method of primary screening for cervical cancer if all resources are available [20] The Papanicolau test (Pap smear) and VIA are other screening tests which have been used to detect premalignant lesions. Early detection of lesions with appropriate intervention reduces related morbidity and mortality. Countries that have established screening programs in the last few decades have seen a significant decline in incidence and deaths due to cervical cancer. Examples include Norway, Sweden, Finland [21, 22]. At the Catholic Hospital in Battor, available records indicate that nearly $50 \%$ of women seeking gynaecological oncology care, are women with cervical cancer. Most of these women present late and the factors associated with their late stage presentation are uncertain. The hospital provides screening services at low cost to patients. In spite of this, service utilization is low and raises concerns about barriers to service use. With the aim of improving uptake of screening services, a study was undertaken to identify sociodemographic, clinical and histological characteristics associated with late presentation of cervical cancer cases reporting to the hospital in the period 2012 to 2016.

\section{Method}

Study design

A cross sectional analytical study design where review of hospital records available at the Outpatient Gynaecological Oncology clinic was conducted. All records of cases seen at the clinic at the Catholic Hospital, Battor and diagnosed with cervical cancer between 2012 and 2016 were reviewed to identify relevant variables for the study.

\section{Patient record selection}

The hospital filing system captured histological reports and medical records of the patients at the gynaecological unit. A total of 159 women diagnosed with cervical cancer were listed in the period under review (Fig. 1). All but two missing records, were collected, arranged chronologically by year of diagnosis and then by month. PD and a trained research assistant selected all records that had most of the variables investigated in the study.

\section{Data collection}

Data abstraction from the patient records was done manually by a trained record clerk using abstraction forms consistent with literature [23]. The abstraction form had separate sections for sociodemographic variables (age, highest level of education attained, marital status, NHIS, employment status, place of residence and distance from hospital), clinical variables (intermenstrual/postmenopausal bleeding, previous screening history, previous smoking history, age at menarche, number of children), histological variables (subtypes of tumour and characteristics of tumour) and stage at presentation (early stage - Stages I \& IIA; late stage - Stages IIB - IV). The selected characteristics were informed by reviewed literature and availability of data in patient records based on the framework in Fig. 2.

\section{Statistical analysis}

Fifty randomly selected abstraction forms were re-checked by EK and PD by comparing with actual records to ensure entries were correct. All data were coded and doubly 


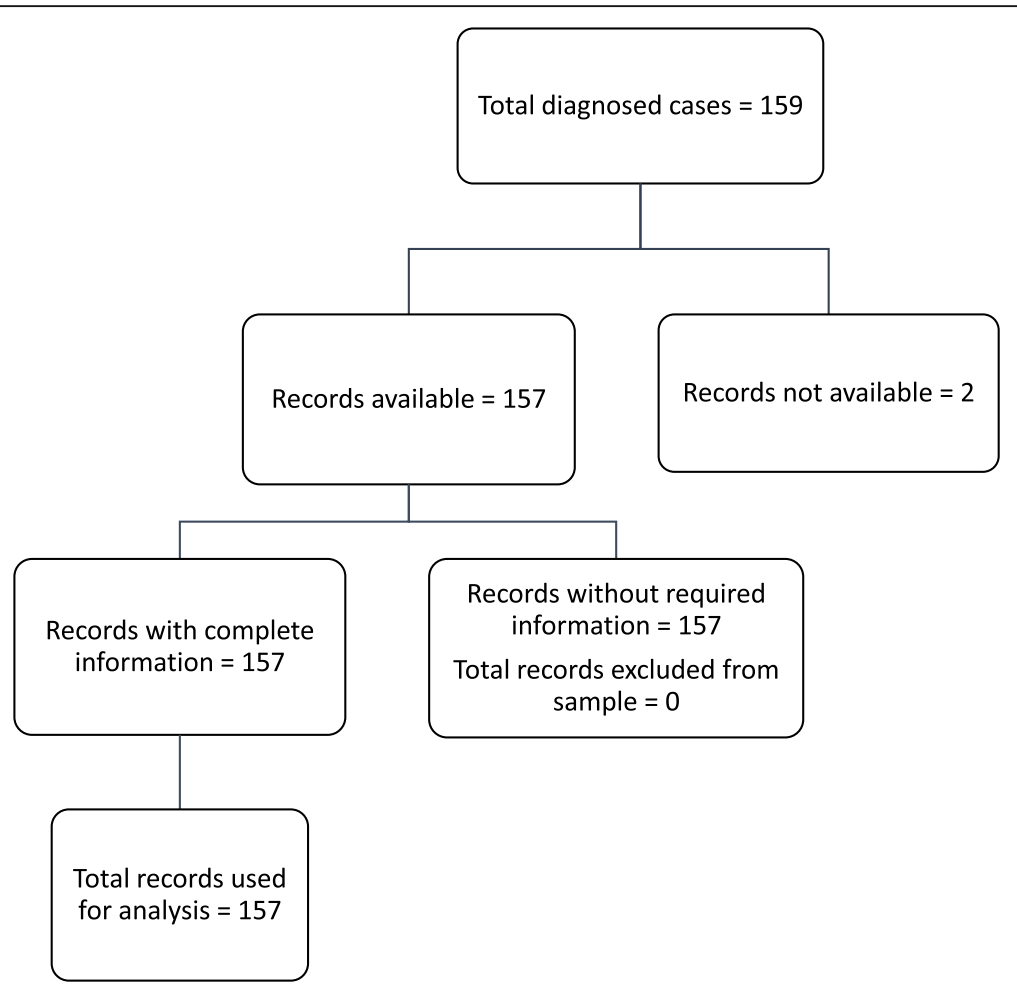

Fig. 1 Schematic diagram showing the record selection process

entered into electronic spreadsheets using Stata version 14. Each variable was scrutinized visually before running the analysis. Descriptive statistics generated included percentages and frequencies of the investigated variables. Some variables such as parity and age of onset of menarche were grouped into dichotomous variables. For parity, two categories (0-4 and 5-12) were used because the total fertility rate in Ghana, being the maximum number of children a woman is expected to have is 4.2 [24]. Additionally, the descriptive summaries for continuous variables yielded a median value of 5 and mean value of 4.85 for parity. This was applied as a threshold to divide parity into two categories namely $<5$ and $\geq 5$ children. Categories for age at menarche were determined in like manner. This variable had a median of 16 years, therefore two groups were created namely: $7-15$ years and $16-25$ years. Furthermore, a Turkish study indicated that the lowest prevalence of cervical cancer was found among women who reported menarche at the age of 15 years or older [25]. The authors were unable to find a similar local study reporting an association between age at menarche and cervical cancer. Cross tabulation of the investigated characteristics and the late stage at presentation of cervical cancer cases was performed using the Pearson's chi-square test and Fischer's exact test where appropriate. Variables that attained statistical significance at a $p$-value of 0.05 or less were further evaluated using logistic regression analysis. Both unadjusted (UOR) and adjusted Odd's ratios (AOR) were computed and the 95\% confidence limits were constructed around the estimates.

\section{Ethical approval}

Ethical approval was sought from the Ethical Review Committee of Ghana Health Service, Research and Development Division, Accra. Clearance to conduct the study was obtained from the District Health Directorate and the hospital management. Data abstraction was done in the conference room of the hospital during hours when it was not in use and to preclude removal of patient records from the hospital. During that time, efforts were made to restrict access to persons directly involved in the research. The trained record clerk was blinded to the research outcome to minimize subjectivity in classification. To protect the identity of the record owners, the abstraction forms did not include the patients' names which were substituted with assigned identification numbers. The master list was stored securely in a pass worded computer, which only the authors had access to. Information from the records were not shared with other individuals outside the research team. Published reports were based on grouped data, precluding the use of individual information.

\section{Results}

\section{Sociodemographic characteristics}

A total of 159 cases of cervical cancer were registered from 2012 to 2016. Of these, 157 (98.74\%) records were 


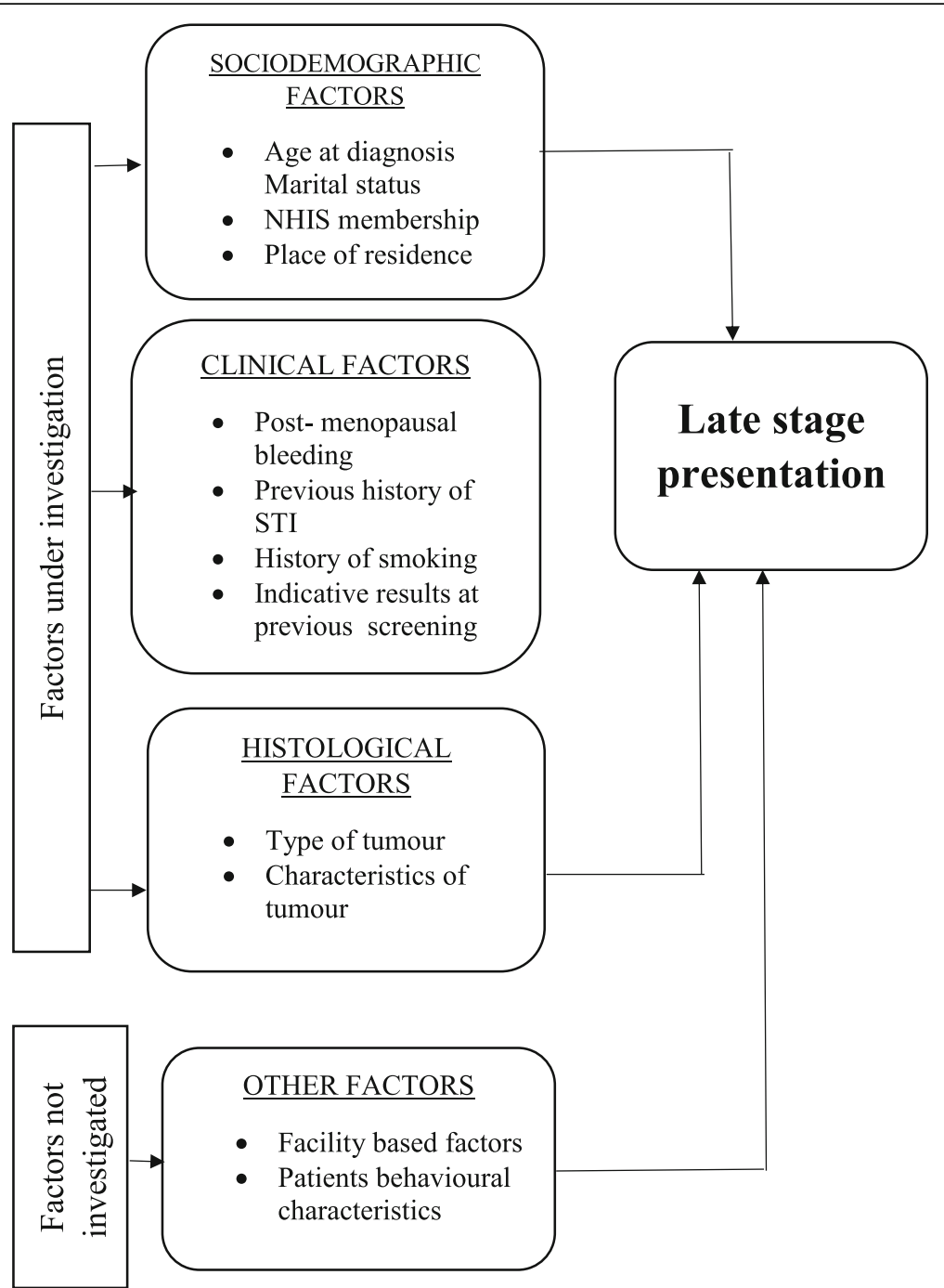

Fig. 2 Conceptual framework for the study

available for review, 2 records were not found. The mean age of the cases was 56.74 [ \pm 15.11 ] years (range: $26-$ 100 years). Among the cases, $55.19 \%$ had no formal education, while the rest attained primary education or higher $(44.81 \%)$. Fifty-one percent of the cases reviewed were married. More than half $(54.78 \%)$ of the cases resided in urban areas and $87.9 \%$ of them were employed. Active membership of the National Health Insurance Scheme (NHIS) was recorded among $86.84 \%$ of cases and $40 \%$ of cases lived more than $100 \mathrm{~km}$ from the study site $(\mathrm{Mdn}=93.1 \mathrm{~km}$; range $0.5 \mathrm{~km}-1084 \mathrm{~km})$. Patient characteristics have been summarized in Table 1 .

\section{Characteristics associated with late stage at presentation of cervical cancer cases}

The hospital based prevalence of late stage at presentation among cervical cancer cases was $65.97 \%$ (95\% CI: $57.61-$
73.65\%). Notably patients who presented late with cervical cancer and had no education comprised three-quarters of the total cases reviewed (Table 2). Of the variables tested for association, only level of education showed significant association with late stage at presentation of cervical cancer cases $\left(\chi^{2}=5.7309 ; \mathrm{df}=1 ; p=0.017\right)$.

The mean age at menarche was 16 years (range 725 years). Among the clinical characteristics, cases that presented late tended to be women who had not been screened previously for cervical cancer $\left(\chi^{2}=7.2840, d f=1\right.$; $p=0.007)$ and those who had menarche between the ages of $16-25$ years $\left(\chi^{2}=5.0264, d f=1 ; p=0.025\right)$ Intermenstrual bleeding, post menopausal bleeding, history of smoking and parity were not associated with late stage at presentation of cervical cases (Table 3).

Variables attaining statistical significance (level of education, age at menarche and previous screening history) 
Table 1 Characteristics of cervical cancer cases

\begin{tabular}{|c|c|c|c|}
\hline Socio-demographic factors & $\mathrm{n}$ & Frequency & Percentage \\
\hline Age (years) & 157 & & \\
\hline$\leq 50$ & & 57 & 36.31 \\
\hline$>50$ & & 100 & 63.69 \\
\hline Highest level of education & 154 & & \\
\hline None & & 85 & 55.19 \\
\hline Primary and above & & 69 & 44.81 \\
\hline Marital Status & 155 & & \\
\hline Never married/single & & 9 & 5.81 \\
\hline Married & & 80 & 51.63 \\
\hline Other (Divorced/ Separated/widowed) & & 66 & 42.58 \\
\hline Employment Status & 157 & & \\
\hline Unemployed & & 19 & 12.10 \\
\hline Employed & & 138 & 87.90 \\
\hline Residence & 157 & & \\
\hline Rural & & 71 & 45.22 \\
\hline Urban & & 86 & 54.78 \\
\hline NHIS Status & 152 & & \\
\hline Insured & & 132 & 86.84 \\
\hline Not Insured & & 20 & 13.16 \\
\hline Distance & 154 & & \\
\hline $0-50 \mathrm{~km}$ & & 24 & 15.58 \\
\hline$>50-100 \mathrm{~km}$ & & 68 & 44.16 \\
\hline$>100 \mathrm{~km}$ & & 62 & 40.26 \\
\hline
\end{tabular}

were included in a regression model, adjusting for age. Sensitivity analysis was performed to assess the effect of missing values from age at menarche, $n=66$ (see Additional file 1). In the first scenario, all the missing records were assumed to belong to women who attained menarche between ages 7-15 years. In the second scenario, all the missing records were assumed to belong to women who attained menarche between ages 1625 years. Results showed that adjusted effect estimates for age (Scenario 1: OR1.05, 95\% CI 0.47-2.33; Scenario 2: OR $0.89,95 \%$ CI 0.39-2.03), level of education (Scenario 1: OR 0.46, 95\% CI 0.22-1.10; Scenario 2: OR 0.51, 95\% CI 0.23-1.12) and screening history (Scenario 1: OR 4.07, 95\% CI 1.47-11.26; Scenario 2: OR 3.40, 95\% CI 1.4311.16) did not change substantially. Therefore, these variables were maintained in the final model (Table 4). Age at menarche was eliminated from the adjusted model. After adjusting for age and level of education, previously unscreened cases of cervical cancer were nearly four times more likely to present late, compared to patients who were screened earlier (OR 3.91, 95\% CI:1.43-10.69) (Table 4). None of the histological characteristics was associated with late stage at presentation of cervical cancer cases (Table 5).
Table 2 Cross tabulation of sociodemographic factors and late stage at presentation of cervical cancer cases

\begin{tabular}{|c|c|c|c|c|}
\hline \multirow{2}{*}{$\begin{array}{l}\text { Socio-demographic } \\
\text { factors }\end{array}$} & \multicolumn{2}{|c|}{ Late stage at presentation } & \multirow[t]{2}{*}{$x^{2}$} & \multirow[t]{2}{*}{$p$-value } \\
\hline & Yes & No & & \\
\hline \multicolumn{5}{|l|}{ Age (years) } \\
\hline$\leq 50$ & $32(61.54)$ & $20(38.46)$ & & \\
\hline$>50$ & $63(68.48)$ & $29(31.52)$ & 0.7127 & 0.399 \\
\hline \multicolumn{5}{|l|}{ Level of education } \\
\hline None & $59(74.68)$ & $20(25.32)$ & & \\
\hline Primary and above & $35(55.56)$ & $28(44.44)$ & 5.7309 & $0.017^{*}$ \\
\hline \multicolumn{5}{|l|}{ Marital Status ${ }^{\S}$} \\
\hline Never married/single & $6(75.00)$ & $2(25.00)$ & & \\
\hline Married & $49(70.00)$ & $21(30.00)$ & & \\
\hline $\begin{array}{l}\text { Other (Divorced/ } \\
\text { Separated/Widowed) }\end{array}$ & $40(65.50)$ & $24(37.50)$ & 1.1004 & $0.643 \S$ \\
\hline \multicolumn{5}{|l|}{ Employment Status ${ }^{\S}$} \\
\hline Unemployed & $13(81.25)$ & $3(18.75)$ & & \\
\hline Employed & $82(64.06)$ & $46(35.94)$ & 1.8715 & $0.263 \S$ \\
\hline \multicolumn{5}{|l|}{ NHIS Status } \\
\hline Insured & $80(65.57)$ & $42(34.43)$ & & \\
\hline Not Insured & $13(72.22)$ & $5(27.78)$ & 0.3109 & 0.577 \\
\hline \multicolumn{5}{|l|}{ Residence } \\
\hline Rural & $43(68.25)$ & $20(31.75)$ & & \\
\hline Urban & $52(64.20)$ & $29(35.80)$ & 0.2598 & 0.610 \\
\hline \multicolumn{5}{|l|}{ Distance } \\
\hline$\leq 50 \mathrm{~km}$ & $14(63.64)$ & $8(36.36)$ & & \\
\hline $51-100 \mathrm{~km}$ & $41(66.13)$ & $21(33.87)$ & & \\
\hline$>100 \mathrm{~km}$ & $37(64.91)$ & 20 (35.09) & 0.0493 & 0.976 \\
\hline
\end{tabular}

$P$-values were based on Pearson chi-square and Fishers exact tests for categorical variables, (\%) represent column percentage, ${ }^{\S}$ Corresponding $p$-value was estimated from Fisher's exact test, ${ }^{*} p$-value from Pearson chi-square test, significant at $95 \%$ confidence level

\section{Discussion}

The study investigated the range of sociodemographic, clinical and histological factors associated with late stage presentation of cervical cancer cases who reported to Gynecological Oncology Care Unit at the Catholic Hospital, Battor from 2012 to 2016. The findings suggest that sociodemographic (no education) and clinical factors (absence of previous screening and age at menarche) influenced late presentation at the study site. Nearly two-thirds of patients with cervical cancer during the stated period reported with advanced stage disease, Similar results were found in studies conducted in Uganda, South India, Iran, Nepal, Tanzania $[4-6,13,14]$ which make it evident that majority of women report with late stage disease, particularly in developing countries.

Other sociodemographic factors (age, marital status, educational level, NHIS, employment status, place of residence and distance) were not associated with late stage at 
Table 3 Cross tabulation of clinical factors and late stage at presentation of cervical cancer cases

\begin{tabular}{|c|c|c|c|c|c|}
\hline \multirow[t]{2}{*}{ Clinical Variables } & \multirow[t]{2}{*}{ N (\%) } & \multicolumn{2}{|c|}{ Late stage presentation } & \multirow[t]{2}{*}{$x^{2}$} & \multirow[t]{2}{*}{$p$-value } \\
\hline & & Yes & No & & \\
\hline Intermenstrual bleeding & 150 & & & & \\
\hline Yes & $34(22.67)$ & $19(61.29)$ & $12(38.71)$ & & \\
\hline No & $116(77.33)$ & $73(67.59)$ & $35(32.41)$ & 0.4275 & 0.513 \\
\hline Post-menopausal bleeding & 148 & & & & \\
\hline Yes & $116(78.38)$ & $73(67.59)$ & $35(32.41)$ & & \\
\hline No & $32(21.62)$ & $18(62.07)$ & $11(37.93)$ & 0.3127 & 0.576 \\
\hline Previous Screening & 151 & & & & \\
\hline Yes & $23(15.23)$ & $9(40.91)$ & $13(59.09)$ & & \\
\hline No & $128(84.77)$ & $84(70.59)$ & $35(29.41)$ & 7.2840 & $0.007^{*}$ \\
\hline Previous Smoking§ & 155 & & & & \\
\hline Yes & $1(0.65)$ & $0(0.00)$ & $1(100.00)$ & & \\
\hline No & $154(99.35)$ & $93(65.96)$ & $48(34.04)$ & 1.9114 & $0.345^{\S}$ \\
\hline Parity & 147 & & & & \\
\hline $0-4$ & $69(46.40)$ & $40(61.54)$ & $25(38.46)$ & & \\
\hline$\geq 5$ & $78(53.60)$ & $49(69.01)$ & $22(30.99)$ & 0.8385 & 0.360 \\
\hline Age at menarche ${ }^{\S}$ & 66 & & & & \\
\hline $7-15$ years & $27(40.91)$ & $9(39.13)$ & $14(60.87)$ & & \\
\hline $16-25$ years & 39 (59.09) & $26(68.42)$ & $12(31.58)$ & 5.0264 & $0.025^{*}$ \\
\hline
\end{tabular}

Percentages-in parentheses; ${ }^{*} p$-values were based on Pearson chi-square and Fishers exact test for categorical variables; (\%) represent column percentage, under Late stage presentation - row percentages are presented, ${ }^{\S} p$-value estimated from Fisher's exact test, ${ }^{*}$ statistically significant when $p<0.05$

presentation of cervical cancer cases. The influence of education was reported in similar studies conducted in Tanzania [5], Nepal [6] and Morocco [16]. This means that women who are educated will be more inclined to report early once they experience an unusual symptom. As most women with cervical cancer present at older ages, age was included to assess how it might affect other factors in the multivariable analysis. In this study, age was not a predictor of late presentation. This finding which contrasts with findings from earlier studies $[8,10,16]$ agrees with a study in
Uganda [4]. In terms of access to healthcare, active membership of the National Health Insurance Scheme was included in the present study. Nevertheless, being uninsured was not associated with late presentation. A potential explanation could be that National Health Insurance does not cover cost of diagnosis, but total abdominal hysterectomy as treatment for early cervical cancer. Moreover, women were dissuaded from seeking medical help related to gynecological issues based on the need to self-fund until symptoms

Table 4 Factors associated with late stage at presentation of cervical cancer cases

\begin{tabular}{|c|c|c|c|c|c|c|}
\hline \multirow[t]{3}{*}{ Covariate } & \multicolumn{6}{|c|}{ Late stage at presentation of cervical cancer cases } \\
\hline & \multicolumn{3}{|c|}{ Unadjusted effect } & \multicolumn{3}{|c|}{ Adjusted effect } \\
\hline & UOR & $95 \% \mathrm{Cl}$ & $p$-value & $\mathrm{AOR}$ & $95 \% \mathrm{Cl}$ & $p$-value \\
\hline \multicolumn{7}{|l|}{ Age } \\
\hline$\leq 50$ years & ref & & & ref & & \\
\hline$>50$ years & 1.43 & $0.70-2.92$ & 0.327 & 1.04 & $0.47-2.30$ & 0.927 \\
\hline \multicolumn{7}{|l|}{ Educational level } \\
\hline No education & ref & & & ref & & \\
\hline Primary and above & 0.45 & $0.22-0.92$ & $0.029 *$ & 0.46 & $0.22-1.02$ & 0.055 \\
\hline \multicolumn{7}{|l|}{ Previous screening } \\
\hline Yes & ref & & & ref & & \\
\hline No & 3.61 & $1.41-9.23$ & $0.007^{*}$ & 3.91 & $1.43-10.69$ & $0.008^{*}$ \\
\hline
\end{tabular}

UOR Unadjusted Odd's Ratio, AOR Adjusted Odd's Ratio, 95\% Cl 95\% confidence level, * statistical significance at 95\% confidence level 
Table $\mathbf{5}$ Cross tabulation of histological factors and late presentation with cervical cancer

\begin{tabular}{|c|c|c|c|c|c|}
\hline \multirow[t]{2}{*}{ Histological Factors } & \multirow[t]{2}{*}{ N (\%) } & \multicolumn{2}{|c|}{ Late Stage Presentation } & \multirow[t]{2}{*}{$x^{2}$} & \multirow[t]{2}{*}{$p$-value } \\
\hline & & Yes & No & & \\
\hline Type of tumour & 148 & & & & \\
\hline Squamous Cell Carcinoma & $116(78.38)$ & $70(66.04)$ & $36(33.96)$ & & \\
\hline Adenocarcinoma/ Adenosquamous/ Other rare types & $32(21.62)$ & $19(63.33)$ & $11(36.67)$ & 0.0756 & 0.783 \\
\hline Characteristics of tumour & 41 & & & & \\
\hline Well differentiated & $11(26.83)$ & $7(70.00)$ & $3(30.00)$ & & \\
\hline Moderately differentiated & $20(48.78)$ & 15 (78.95) & $4(21.05)$ & & \\
\hline Poorly differentiated & $8(19.51)$ & $4(57.14)$ & $3(42.86)$ & & \\
\hline Undifferentiated & $2(4.88)$ & $1(50.00)$ & $1(50.00)$ & 1.6706 & $0.500^{\S}$ \\
\hline
\end{tabular}

$P$-values in parentheses, (\%) represent column percentage, ${ }^{5} p$-value estimate from Fisher's exact test

become worse. In other studies, insurance covered the full management of cervical cancer [10-12].

The hospital is surrounded by rural communities, women who seek gynecological cancer care come from both rural and urban settings. Studies in the United States [15], Sudan [10] and Morocco [16] reported an association with rural urban residence, while studies in Uganda [4], and Nepal [6] did not report any association as in the present study. Being that the present study was conducted retrospectively, ascertaining average monthly income was not possible hence employment status was used as a proxy. Income generation can be used in determining the socioeconomic status of an individual as low socioeconomic status has been found to have a pronounced effect on late presentation $[4,14]$. Employment status was used as a proxy measure to indicate income generation and suggests that a woman might have the capacity to care for her own health rather than relying on her partner or family relations, as in the case of unemployed women. Interestingly, this factor did not predict late stage at presentation with cervical cancer, compared to studies conducted in Uganda [4] and Iran [14]. It is expected that due to lack of money, women will not seek early care until symptoms becomes worse. Among all clinical variables (intermenstrual bleeding, previous screening history, smoking history, number of children and age at menarche) studied, only cases that did not undergo previous screening for cervical cancer and cases that reported older ages at menarche were independently associated with late presentation. A previous study in Iran [14] also reported a significant association with not having been screened previously. Women who have cervical lesions that are not detected early may progress to advanced disease without intervention. The older age at menarche was an unusual finding as it has not been reported previously in local studies or in the studies reviewed in this research. As the statistical association was not maintained in the results from the sensitivity analysis, this variable was omitted from the adjusted model. The authors have reconstructed the original conceptual framework to summarize the study results (Fig. 3).

\section{Limitations}

It is noteworthy that this study had some limitations. Firstly, the study being a retrospective study relied solely on the medical records. No additional information could be collected as the patients were not physically present. For example; although literature reports HIV status, contraceptive use and sexually transmitted infections as relevant clinical factors associated with cervical cancer, these were not documented in the records by the attending medical personnel in the period under study. Additionally, some missing data were observed for most of the variables investigated. This particularly affected age at menarche and the histopathology results. The missing data on age at menarche can be attributed to some sociocultural factors such as lack of education about menstruation by parents and guardians due to embarrassment in addressing the subject. There is also much emphasis placed on instilling fear about getting pregnant, rather than keeping personal record of gynaecological information such as menarche. The histopathology results often did not report on the tumour sub-type and characteristics of tumour. These omissions might have resulted from either the record personnel, the attending physician or the patient if she was unable or unwilling to supply the required information. Other cases that may not have reported at the facility in the time frame were excluded, so the actual prevalence could probably be higher.

A sensitivity analysis was conducted to assess the effect of the extent of missing values on the logistic regression model. In the first scenario, it was assumed that all missing records of age at menarche belonged to women who attained menarche in the age range 7-15 years. In the second scenario, it was assumed that all the missing records of age at menarche belonged to women who attained menarche in the age range 16-25 years. In both models, the absence of previous screening remained a significant factor 


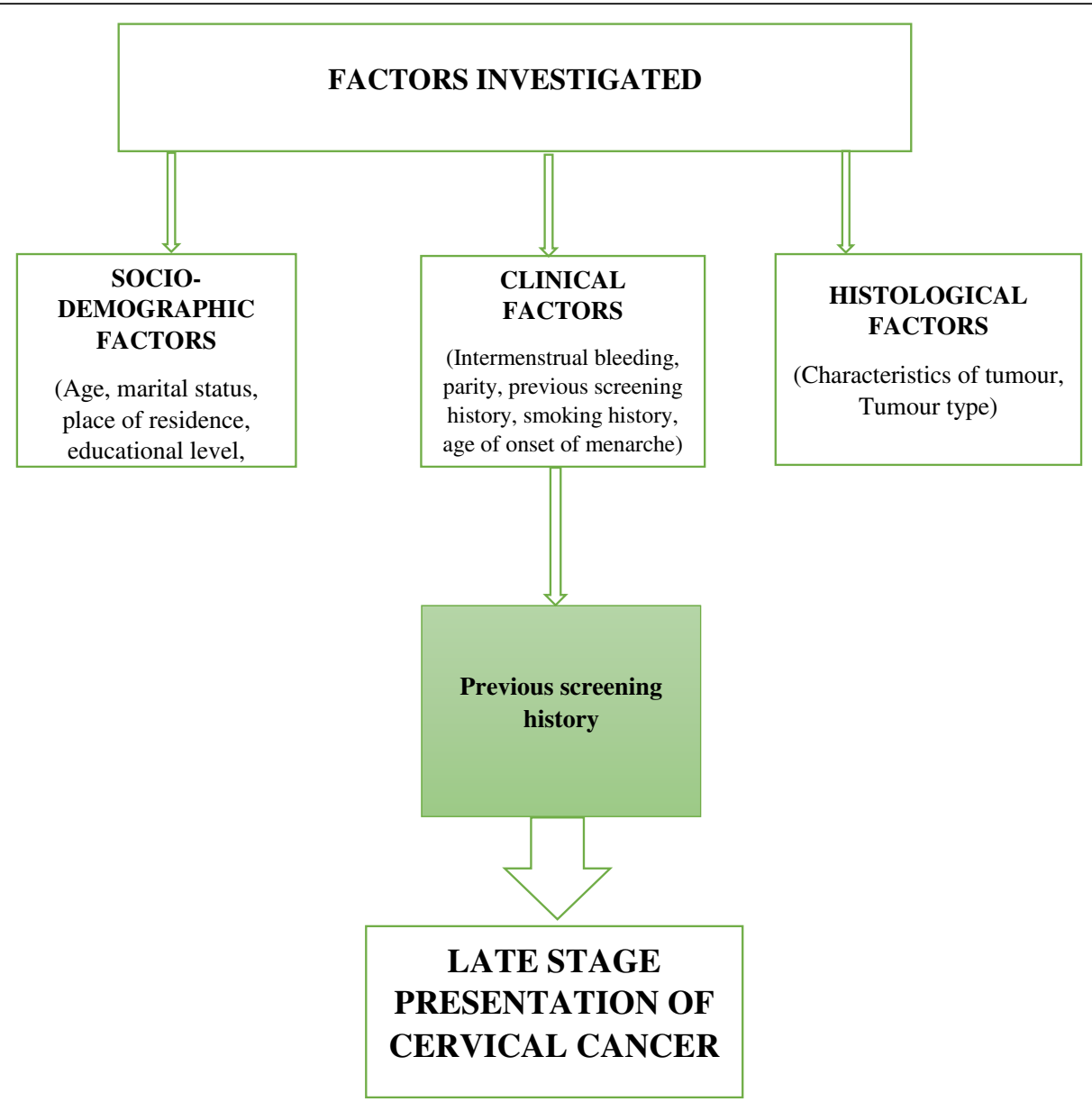

Fig. 3 Framework explaining late presentation of cervical cancer cases at Catholic Hospital, Battor

associated with late stage at presentation of cervical cancer cases. However, age at menarche was not always associated with late presentation of cervical cancer. Therefore, the extent of missing values for age at menarche makes it difficult to conclude definitively that age at menarche is associated with late presentation of cervical cancer.

\section{Future directions}

In view of the findings, the following are recommended at community level:

1. The creation of an advocacy tool using a pictorial illustration to highlight study findings. This can be employed to create awareness and support cancer education at the Gynecological Oncology care unit. The tool should show the link between absence of screening and late stage at presentation. This would explain why women need to be screened early.

Simple information should be included about places where women can get screened and time of availability of the service. The tool can be field tested and replicated for use during home visits made by community health workers and should target adult women. Further research will be required to assess the impact of the tool in improving screening rates in Battor, using the present study as a baseline.

2. Focus groups can be held with male and female groups to explore barriers to screening and find local solutions to address them. Engaging the support of male partners for increased uptake of preventive screening by women is a pro-active step. This is because male partners can provide funds to pay for the service and thereby influence health seeking behaviour.

3. The study findings should be disseminated. The media and local durbars offer the opportunity to increase awareness and advocate support from donor groups, civil society and private agencies to help equip additional service units so that services can have a wider reach. The provision of gift vouchers to facilitate screening and subsidize treatment costs by corporate organizations would be a meaningful addition. 
4. The relationship with age at menarche can be explored further in future research if women are informed about the importance of keeping relevant information.

At the national level, the following are recommended:

1. Training of public health nurses, physician assistants and community health workers in preventive screening and supporting them with required logistics could be a way to decentralize services and make screening more accessible to women. This can be organized by Ghana Health Service in collaboration with local oncologists.

2. Consideration should be given to the inclusion of cancer screening and early treatment under the National Health Insurance Scheme. This is recommended as an adjunct measure to other recommendations as its merit lacked statistical support in the study, but it can offer potential benefits.

3. Standard guidelines for screening should be provided in consulting rooms and/or service units which should be supported with the necessary logistics.

4. Health education for in-school and out of school youth should provide information about keeping personal records of important developmental landmarks like menarche in the case of females. Physically challenged adolescent females can be assisted by teachers, guardians or a significant other person to maintain relevant health records, which should help attending physicians capture their data for analysis. Health workers can only record information that is provided by their patients voluntarily. Women will be encouraged to offer such information provided that they understand why it is relevant to keep account of it.

\section{Conclusion}

Three factors tended to be associated with late stage presentation of cervical cancer cases at Battor, namely lack of formal education, the absence of previous screening and older age at menarche. However, only absence of previous screening was predictive of late stage presentation of cervical cancer cases. As nearly two thirds of the cases presented in advanced stages of cervical cancer, efforts to promote early cervical cancer screening should be intensified. Further studies are required to investigate a relationship with age at menarche.

\section{Additional file}

Additional file 1: Authors' original file for the sensitivity analysis showing two scenarios. (DOCX $18 \mathrm{~kb}$ )

\section{Abbreviations}

95\% Cl: 95\% Confidence interval; AOR: Adjusted odd's ratio;

DNA: Deoxyribonucleic acid; NHIS: National Health Insurance Scheme;

UOR: Unadjusted odd's ratio; VIA: Visual Inspection with Acetic Acid

\section{Acknowledgements}

The authors acknowledge with gratitude the support of the management and staff of Catholic Hospital, Battor, and the Cervical Cancer Prevention and Training Centre in particular. They are deeply grateful to the records staff for their untiring efforts during the abstraction of data and to the women whose data contributed to this publication.

\section{Availability of data and materials}

The datasets generated and/or analyzed during the current study are not publicly available as they contain confidential information that could compromise privacy but non-identifiable aspects can be made available upon reasonable request.

\section{Authors' contributions}

PD conceptualized, designed the study and coordinated field work; KE contributed to field work and data quality; EA contributed to proposal development and preliminary analysis of data. All authors contributed to drafting the manuscript, reviewed and approved the final version.

\section{Ethics approval and consent to participate}

The Ethical Review Committee of Ghana Health Service, Research and Development Division, Accra approved the research (GHS-ERC: 74/02/17)

Consent for publication

Not applicable.

\section{Competing interests}

The authors declare that they have no competing interests.

\section{Publisher's Note}

Springer Nature remains neutral with regard to jurisdictional claims in published maps and institutional affiliations.

\section{Author details}

${ }^{1}$ Department of Population, Family and Reproductive Health, School of Public Health, University of Ghana, Legon, Accra, Ghana. ${ }^{2}$ Obstetric and Gynecological Department/Cervical Cancer Screening and Training Center, Catholic Hospital, Battor, Ghana. ${ }^{3}$ Department of Community Health, School of Public Health, University of Ghana, Legon, Accra, Ghana.

Received: 25 January 2018 Accepted: 24 September 2018 Published online: 03 October 2018

References

1. Bruni L, Barrionuevo-Rosas L, Albero G, Serrano B, Mena M, Gómez D, Muñoz J, Bosch FX, de Sanjose. S. Human Papillomavirus and Related Diseases Report. ICO Information Centre on HPV and Cancer (HPV Information Centre). Human Papillomavirus and Related Diseases in Ghana, (October, 2016). Retrieved from www.hpvcentre.net.

2. Handlogten KS, Molitor RJ, Roeker LE, Narla NP, Bachman MJ, Quayson S, et al. Cervical Cancer screening in Ghana, West Africa. Int J Gynecological Pathology. 2014; https://doi.org/10.1097/PGP.0b013e318298a9e6.

3. NSCCG. Cervical Cancer. National Strategy for Cancer control in Ghana. Accra: Ministry Of Health, Ghana. 2011;2011:20-2.

4. Mwaka, A. D., Garimoi, C. O., Were, E. M., Roland, M., Wabinga, H., \& Lyratzopoulos, G. Social, demographic and healthcare factors associated with stage at diagnosis of cervical cancer : cross-sectional study in a tertiary hospital in Northern Uganda, 2016; 6(1):1-10. https://doi.org/10.1136/ omjopen-2015-007690

5. Mlange R, Matovelo D, Rambau P, Kidenya B. Patient and disease characteristics associated with late tumour stage at presentation of cervical cancer in northwestern Tanzania. BMC Womens Health. 2016;16(5) https:// doi.org/10.1186/s12905-016-0285-7.

6. Stewart TS, Moodley J, Walter F. Population risk factors for late stage presentation of cervical cancer in sub-Saharan African. Cancer Epidemiol. 2018;53:81-92 https://doi.org/10.1016/j.canep.2018.01.014. 
7. Nartey Y, Hill PC, Cox B, Philip C, Amo-Antwi K, Nyarko KM, Yarney J. Cervical Cancer in the Greater Accra and Ashanti regions of Ghana. J Glob Oncol. 2017;3(6):782-90. https://doi.org/10.1200/JGO.2016.005744.

8. Saghari S, Ghamsary M, Marie-mitchell A, Oda K, Morgan WJ. Annals of epidemiology sociodemographic predictors of delayed- versus early-stage cervical cancer in California. Ann Epidemiol. 2015;25(4):250-5 https://doi. org/10.1016/j.annepidem.2015.01.008.

9. Tanturovski D, Zafirova E, Stojovski M, Basheska N, Jovanovska V. Impact of socio-demographic factors on the delayed diagnosis and advanced stage presentation of patients with invasive cervical cancer in Macedonia. CONTRIBUTIONS Sec Med Sei. 2013;34(3):71-8.

10. Ibrahim A, Rasch V, Pukkala E, Aro AR. Predictors of cervical cancer being at an advanced stage at diagnosis in Sudan. Int J Women's Health. 2011;3:385.

11. Ferrante JM, Gonzalez EC, Roetzheim RG, Pal N, Woodard L. Clinical and demographic predictors of late-stage cervical cancer. Arch Fam Med. 2000; 9(5):439.

12. Amini A, Jones BL, Yeh N, Guntupalli SR, Kavanagh BD, Karam SD, Fisher CM. Disparities in disease presentation in the four screenable cancers according to health insurance status. Public Health. 2016;138:50-6 https://doi.org/10. 1016/j.puhe.2016.03.014.

13. Kaku M, Mathew A, Rajan B. Impact of socio-economic factors in delayed reporting and late-stage presentation among patients with cervix cancer in a major cancer hospital in South India. Asian Pac J Cancer Prev. 2008;9(4): 589-94.

14. Behnamfar F, Azadehrah M. Factors associated with delayed diagnosis of cervical cancer in Iran - a survey in Isfahan city. Asian Pac J Cancer Prev. 2015;16(2):635-9.

15. Barry, J., \& Breen, N. (2005). The importance of place of residence in predicting late-stage diagnosis of breast or cervical cancer, 11, 15-29. https://doi.org/10.1016/j.healthplace.2003.12.002.

16. Berraho M, Obtel M, Bendahhou K, Zidouh A, Errihani H, Benider A, Nejjari C. Sociodemographic factors and delay in the diagnosis of cervical cancer in Morocco. Pan African Med J. 2012;12(1)

17. Ndlovu N, Kambarami R. Factors associated with tumour stage at presentation in invasive cervical cancer. The Central African Journal of Medicine. 2003;49(9-10):107-11.

18. Symonds $\mathrm{P}$, Bolger B, Hole D, Mao JH, Cooke T. Advanced-stage cervix cancer: rapid tumour growth rather than late diagnosis. $\mathrm{Br} J$ Cancer. 2000; 83(5):566-8 https://doi.org/10.1054/bjoc.2000.1336.

19. Thuler LCS, De Aguiar SS, Bergmann A. Determinant of late stage diagnosis of cervical cancer in Brazil. Revista Brasileira de Ginecologia E Obstetrícia. 2014;36(6):237-43 https://doi.org/10.1590/S0100-720320140005010.

20. Jeronimo J, Castle PE, Temin S, Denny L, Gupta V, Kim Jane J, Luciani S, Murokora D, Ngoma T, Quinn M, Sankaranarayanan R, Sasieni P, Schmeler KM, Shastri SS. Secondary Prevention of Cervical Cancer : ASCO ResourceStratified Clinical Practice Guideline executive summary, 2016. Global Oncology. 2017;3(5):635-57.

21. Sankaranarayanan R, Shyamalakumary B, Wesley R, Amma NS, Parkin DM. M K N (1999) Visual inspection with acetic acid in the early detection of cervical cancer and precursors Ear and Hearing. 1999;35(4):485-6 https://doi. org/10.1097/AUD.0000000000000018.

22. Larønningen, S., Larsen, I. K., Møller, B., Engholm, G., Storm, H. H., \& Johannesen, T. B. Special issue : NORDCAN Cancer data from the Nordic countries, 2013.

23. Pan L, Fergusson D, Schweitzer I, Hebert PC. Ensuring high accuracy of data abstracted from patient charts: the use of a standardized medical record as a training tool. J Clin Epidemiol. 2005;58(9):918-23 https://doi.org/10.1016/j. jclinepi.2005.02.004.

24. Ghana Statistical Service (GSS), Ghana Health Service (GHS), and ICF International Ghana Demographic and Health Survey. Rockville. USA: Maryland; 2014. p. 60.

25. Reis N, Beji NK, Kilic D. Risk factors for cervical cancer: Results from a hospital based-study case-control study. 2011;21(3):153-9.

Ready to submit your research? Choose BMC and benefit from:

- fast, convenient online submission

- thorough peer review by experienced researchers in your field

- rapid publication on acceptance

- support for research data, including large and complex data types

- gold Open Access which fosters wider collaboration and increased citations

- maximum visibility for your research: over $100 \mathrm{M}$ website views per year

At BMC, research is always in progress.

Learn more biomedcentral.com/submissions 